\title{
Augmentation of pulmonary host defense against Pseudomonas by Fo $\gamma$ RIIA cDNA transfer to the respiratory epithelium
}

\author{
Stefan Worgall, ${ }^{1}$ Petr Bezdicek, ${ }^{1}$ Moo-Kyung Kim, ${ }^{2}$ Jong-Gu Park, ${ }^{3}$ \\ Ravi Singh, ${ }^{1}$ Melpo Christofidou-Solomidou, ${ }^{2}$ Alice Prince, ${ }^{4}$ \\ Imre Kovesdi, ${ }^{5}$ Alan D. Schreiber, ${ }^{2}$ and Ronald G. Crystal ${ }^{1}$ \\ ${ }^{1}$ Division of Pulmonary and Critical Care Medicine, The New York Hospital-Cornell Medical Center, New York, New York 10021, USA
2Department of Medicine, The University of Pennsylvania School of Medicine, Philadelphia, Pennsylvania 19104, USA
${ }^{3}$ InKine Pharmaceutical Company Inc., Blue Bell, Pennsylvania 19422, USA
${ }^{4}$ Division of Infectious Diseases, College of Physicians and Surgeons, Columbia University, New York, New York 10032, USA
${ }^{5}$ GenVec Inc., Rockville, Maryland 20852 USA
}

Address correspondence to: S. Worgall, The New York Hospital-Cornell Medical Center, 520 East 70th Street, ST 505, New York, New York 10021, USA. Phone: (212) 746-2258; Fax: (212) 746-8383; E-mail: geneticmedicine@mail.med.cornell.edu.

Stefan Worgall and Petr Bezdicek contributed equally to this work.

Received for publication October 6, 1998, and accepted in revised form July 13, 1999.

Fc $\gamma$ receptors on the surface of phagocytic cells bind the Fc region of IgG and mediate binding, phagocytosis, and destruction of particulate antigens opsonized by the antigen-specific IgG molecule. The present study evaluates the feasibility of converting lung epithelial cells into phagocytic cells using adenovirus (Ad) vector-mediated gene transfer of Fc $\gamma$ RIIA cDNA to induce expression of the human Fc $\gamma$ RIIA receptor. Binding and phagocytosis of opsonized sheep red blood cells (SRBCs) by the A549 human lung epithelial cell line after Ad-mediated Fc $\gamma$ RIIA gene transfer was demonstrated using light and fluorescence microscopy and phagocytic assays with ${ }^{51}$ Cr-labeled SRBCs. When A549 cells were infected with an Ad vector expressing a Fc $\gamma$ RIIA mutant in which 2 of 3 cytoplasmic tyrosines have been replaced with phenylalanine, only binding, but not phagocytosis, of opsonized SRBCs was observed. In vivo expression of Fc $\gamma$ RIIA in the lung after intratracheal administration of the AdFc $\gamma$ RIIA enhanced clearance of opsonized Pseudomonas aeruginosa from the lung in normal rats and in mice deficient in Fc $\gamma$ receptor expression. Similar results were observed with a chimeric Fc $\gamma$ RIIA construct containing the extracellular domain of Fc $\gamma$ RIIIA. Together, these data demonstrate that Ad-mediated Fc $\gamma$ RIIA receptor cDNA expression can mediate the binding and phagocytosis of opsonized particulate antigens by normally nonphagocytic cells, suggesting that gene-transfer strategies might be used to utilize nonphagocytic cells to clear bacteria or other opsonized particulate antigens from the respiratory tract.

J. Clin. Invest. 104:409-418 (1999).

\section{Introduction}

The lung has evolved a variety of mechanisms to deal with microorganisms that evade the defenses of the upper airways and are deposited on the respiratory epithelial surface (1). After the first-line innate immune defenses such as the mucous barrier, mucociliary activity, and locally produced peptide antibiotics $(2,3)$, the next line of defense is the phagocyte system, including alveolar macrophages resident on the epithelial surface and neutrophils recruited to the lung $(4,5)$. Phagocytes can ingest microorganisms directly or after they are coated with surfactant proteins or complement, but the most efficient mechanism of phagocytosis is the ingestion of IgG-coated microorganisms via IgG Fc receptors (Fc $\gamma$ receptors) on the phagocyte surface (6). The interaction of these receptors with their cognate IgG complexed to a microorganism leads to rapid engulfment and destruction of the opsonized targets. There are 3 classes of Fc $\gamma$ receptors (Fc $\gamma R$ ): Fc $\gamma R I$ (CD64), Fc $\gamma R I I$

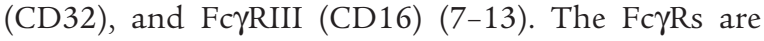
encoded by at least 8 genes, and, together with alterna- tive mRNA splicing, the result is a broad diversity of $\mathrm{Fc} \gamma \mathrm{R}$ isoforms. Each Fc $\gamma$ receptor is composed of a chain containing the ligand-binding site, and some $\mathrm{Fc} \gamma$ receptors (FcyRIA, Fc $\gamma$ RIIIA) are expressed as a multisubunit receptor complex in association with a non-IgG-binding subunit $(\gamma$ and/or $\zeta)(7-13)$.

The identification and characterization of the Fc $\gamma \mathrm{R}$ (7-13) and the development of strategies to transfer and express exogenous genes in the airway epithelium (14-17) has led us to hypothesize that transient transfer and expression of FcyR in the airway epithelium might enable the epithelium to bind and ingest opsonized microorganisms, and thus provide an additional pulmonary host defense strategy against infectious agents. To evaluate this concept, we have used a replication-deficient adenovirus (Ad) vector to transfer human Fc $\gamma$ RIIA cDNA to the airway epithelium of experimental animals. We then challenged the animals with an intratracheal burden of Pseudomonas aeruginosa. The data demonstrate that the strategy of transiently enabling the epithelium to phagocytize Pseudomonas can provide a new level of 
host defense that may be useful in helping to reduce the burden of an infectious agent in the lung.

\section{Methods}

Adenovirus vectors. The replication-deficient recombinant Ad vectors AdFc $\gamma$ RIIA, AdFc $\gamma$ RIIA mutant, and AdNull are all E1a, partial E1b, and partial E3 vectors based on adenovirus type 5 (Ad5), in which an expression cassette containing a promoter driving the expression of a recombinant gene is inserted at the site of the E1 deletion (15). The AdFc $\gamma$ RIIA vector contains an expression cassette of the cytomegalovirus early/intermediate promoter/enhancer followed by an artificial splice, the human FcyRIIA cDNA $(18,19)$, and the SV-40 stop/poly(A) signal (20). The AdFc $\gamma$ RIIA mutant vector is similar but contains a mutated human Fc $\gamma$ RIIA cDNA in which 2 of 3 cytoplasmic tyrosines (Y282 and Y298) $(19,21)$ have been replaced with phenylalanine, rendering the receptor unable to deliver appropriate intracellular signals and thus able to bind an opsonized antigen, but unable to signal the cell to ingest the antibody-antigen complex. AdNull is identical, except that it lacks a gene in the expression cassette (20). AdFc $\gamma$ RIIIA is a new Fc $\gamma$ RIIA construct containing the extracellular domain of Fc $\gamma$ RIIIA and the transmembrane and cytoplasmic

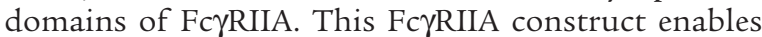
detection of the IgG-coated bacteria by the extracellular domain of Fc $\gamma$ RIIIA, and similar chimeric Fc $\gamma$ receptors function efficiently in inducing phagocytosis in epithelial cells $(22,23)$. The Ad vectors were propagated, purified, and stored at $-70^{\circ} \mathrm{C}$ as described previously $(14,15)$. Titers of viral preparations were determined by plaque assay using 293 cells (24). All preparations were free of replication-competent $\mathrm{Ad}(17)$.

Expression of FcyRIIA in A549 cells. A549 cells, a lung epithelial cell line derived from a human lung carcinoma, were obtained from American Type Culture Collection (CCL-185; Manassas, Virginia, USA) and grown on 6-well tissue culture plates (Becton Dickinson Labware, Franklin Lanes, New Jersey, USA) in F-12K Nutrient Mixture (Kaighn's Modification; GIBCO BRL, Gaithersburg, Maryland, USA) with 10\% FBS (GIBCO BRL), glutamine (2 mM; Biofluids Inc., Rockville, Maryland, USA), penicillin $\mathrm{G}(50 \mathrm{U} / \mathrm{mL}$; GIBCO BRL) and streptomycin (50 $\mu \mathrm{L} / \mathrm{mL}$; GIBCO BRL).

To assess expression of the Fc $\gamma$ RIIA mRNA in vitro, A549 cells were infected with AdFc $\gamma$ RIIA at 1 and 10 moi, using noninfected cells as controls. Total RNA was extracted (RNA Extraction Kit; CLONTECH Laboratories Inc., Palo Alto, California, USA) and transferred (10 $\mu \mathrm{g} /$ lane) to nylon membranes after electrophoretic separation through a $1 \%$ agarose gel. The membranes were hybridized using a human Fc $\gamma$ RIIA cDNA probe labeled with $\left.{ }^{32} \mathrm{P}\right] \mathrm{dCTP}$ (Random Primer Labeling Kit; Stratagene, La Jolla, California, USA) for 2 hours using standard methods (25). A ${ }^{32}$ P-labeled human GAPDH probe was used as a positive control (26).

To evaluate the expression of Fc $\gamma$ RIIA protein on the surface of A549 cells after Ad-mediated gene transfer by immunohistochemistry, A549 cells were infected with AdFc $\gamma$ RIIA and AdNull at 10 moi. After 48 hours, the cells were fixed in $4 \%$ paraformaldehyde (Electron
Microscopy Sciences, Fort Washington, Pennsylvania, USA) in PBS and incubated with anti-Fc $\gamma$ RIIA mAb IV.3 ( $5 \mu \mathrm{g} / \mathrm{mL}$; Medarex Inc., Annandale, New Jersey, USA) (13) for 8 hours or, as a control, with an isotype-matched mouse mAb (IgG2b; Sigma Chemical Co., St. Louis, Missouri, USA). The cells were then washed, and the antibody was detected with alkaline phosphatase-conjugated goat anti-mouse IgG (Sigma Chemical Co.) for 60 minutes. The cells were then washed, incubated for 10 minutes with alkaline phosphatase substrate (new fuchsin; DAKO Corp., Carpinteria, California, USA), and counterstained for 60 seconds with undiluted hematoxylin (Sigma Chemical Co.).

To quantify surface expression of FcyRIIA by flow cytometry analysis (EPICS XL; Coulter Corp., Miami, Florida, USA), A549 cells were infected with AdFc $\gamma$ RIIA or AdNull at 10 moi, using noninfected cells as an additional control. The cells were incubated with PBS solution $(\mathrm{pH}$ 7.4; GIBCO BRL) containing $2 \%$ goat serum on ice for 30 minutes followed by the mouse anti-FcyRIIA mAb IV.3 (20 $\mu \mathrm{g} / \mathrm{mL}$ ) for 30 minutes on ice. The cells were then washed in PBS, incubated with FITC-conjugated goat anti-mouse [F( $\left.\left.\mathrm{ab}^{\prime}\right) 2\right]$ fragments (Roche Molecular Biochemicals, Indianapolis, Indiana, USA) for 30 minutes, washed in PBS, fixed in $1 \%$ paraformaldehyde (Sigma Chemical Co.), and analyzed by flow cytometry. An isotype-matched mouse $\mathrm{mAb}$ (IgG2b; Sigma Chemical Co.) was analyzed as a negative control.

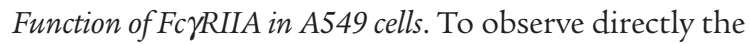
ability of AdFc $\gamma$ RIIA infection of A549 cells to enhance binding of opsonized sheep red blood cells (SRBCs), A549 cells were grown in Corning $35-\mathrm{mm}$ tissue culture dishes (Corning Inc., Corning, New York, USA) modified by punching a $7-\mathrm{mm}$-diameter hole in the bottom and resealing with $22 \times 22 \mathrm{~mm}$ no. 1 glass coverslip (Clay Adams Gold Seal; VWR Inc., South Plainfeild, New Jersey, USA) with a melted solution of paraffin and petroleum jelly (3:1) (27) and were infected with AdFcyRIIA, AdFc $\gamma$ RIIA mutant, or AdNull at 10 moi. After 48 hours, the A549 cells were incubated with IgG-coated SRBCs (Accurate Chemical \& Scientific Corp., Westbury, New York, USA) for 60 minutes or, as a negative control, with nonopsonized SRBCs. To evaluate binding, cells were washed with PBS, fixed in 4\% paraformaldehyde (Sigma Chemical Co.), and stained by a Giemsa stain (J.T. Baker, Phillipsburg, New Jersey, USA).

To observe AdFc $\gamma$ RIIA-induced phagocytosis directly, A549 cells were grown and infected as already described here. The cells were incubated with SRBCs and washed in PBS 3 times, and the SRBCs bound to the cell surface but not internalized were lysed by incubation with hypotonic lysing buffer ( $31 \mathrm{mM}$ ammonia chloride, $2 \mathrm{mM}$ potassium bicarbonate, $20 \mu \mathrm{M}$ ethylenediaminotetraacetic acid; all from Sigma Chemical Co.) for $60 \mathrm{sec}-$ onds. The cells were then fixed in $4 \%$ paraformaldehyde and stained by a Giemsa stain. To view cell-associated SRBCs, 4 unstained cultures were treated with $1 \%$ alcoholic eosin (EM Science, Hawthorne, New York, USA) for 30 seconds, rinsed 3 times in PBS ( $\mathrm{pH}$ 7.4; Biofluids Inc.), and mounted with $10 \%$ glycerol using glass coverslips. Cells were viewed using a Nikon Microphot SA microscope equipped with a $\times 40$ PlanApo objective, $100 \mathrm{~W}$ 
mercury arc, and a Nikon Texas red filter set (both from Nikon Inc., Melville, New York, USA). Before capturing images, samples were exposed to epifluorescence illumination for 30 seconds to bleach background eosin staining and to expose eosin-stained SRBCs.

The function of the Fc $\gamma$ RIIA protein expressed by A549 cells after Ad-mediated gene transfer was determined in vitro by quantification of binding and phagocytosis of IgGopsonized ${ }^{51} \mathrm{Cr}$-labeled SRBCs. The A549 cell/SRBC ratio for all incubations was 1:500. A549 cells $\left(5 \times 10^{5}\right.$ per well $)$ were infected with AdFc $\gamma$ RIIA at 10 moi, using AdFc $\gamma$ RIIA mutant- and AdNull- infected cells, and noninfected cells as controls. After 48 hours, the cells were incubated for 60 minutes with an IgG rabbit anti-SRBC antibody-coated (Accurate Chemical \& Scientific Corp.), ${ }^{51} \mathrm{Cr}$-labeled (Du Pont NEN Research Products, Boston, Massachusetts, USA) SRBCs (Accurate Chemical \& Scientific Corp.). Nonopsonized, ${ }^{51} \mathrm{Cr}$-labeled SRBCs were used as controls. To evaluate binding of IgG- ${ }^{51} \mathrm{Cr}$-labeled SRBCs to the Fc $\gamma$ RIIA cDNA-modified cells, the A549 cells were washed 3 times in PBS and then lysed by incubation in $0.5 \%$ SDS solution (Sigma Chemical Co.) for 10 minutes on ice (28). To evaluate phagocytosis, A549 cells were incubated with IgG- ${ }^{51} \mathrm{Cr}$-labeled SRBCs for 60 minutes, washed 3 times in PBS, incubated for 60 seconds in hypotonic lysing buffer to lyse bound noninternalized SRBCs, and then lysed in $0.5 \%$ SDS for 10 minutes on ice. The radioactivity of the lysate was measured using a gamma counter.

To evaluate internalization of opsonized bacteria, A549 cells were infected with AdFcyRIIA, AdFcyRIIA mutant, or AdNull. Forty-eight hours later, the cells were infected with $3 \mathrm{CFU} /$ cell of opsonized $P$. aeruginosa (PAO1 nonmucoid laboratory strain) (29). The bacteria were grown at $37^{\circ} \mathrm{C}$ in tryptic soy broth (Difco Laboratories, Detroit, Michigan, USA) to the midlog phase, washed in PBS, and opsonized by incubation for $30 \mathrm{~min}-$ utes with rabbit anti-PAO1 polyclonal antibody (1:200 dilution) at $37^{\circ} \mathrm{C}$. After 30 minutes, the cells were washed and lysed with $0.5 \%$ Triton X-100 (Sigma Chemical Co.), and the bacterial counts were determined by 18 hour cultures of serial dilutions at $37^{\circ} \mathrm{C}$ on $1.5 \% \mathrm{Mac}-$ Conkey agarose (Difco Laboratories) plates. To evaluate bacterial clearance by other lung cell lines, the human lung epithelial cell lines HS 24 or BET-1A, infected with AdFc $\gamma$ RIIA, were infected with opsonized Psendomonas or Staphylococcus aureus for 60 minutes, and the number of bacteria was determined by culturing the bacteria from the supernatant.

In vivo expression of Fc $\gamma$ RIIA. To evaluate expression of the Fc $\gamma$ RIIA cDNA in vivo, female Sprague-Dawley rats (250-300 g; Taconic Farms, Germantown, New York, USA) were anesthetized with intramuscular injection of ketamine $(60 \mathrm{mg} / \mathrm{kg}$; Fort Dodge Lab Inc., Fort Dodge, Iowa, USA) and xylazine ( $5 \mathrm{mg} / \mathrm{kg}$; Buttler Co., Columbus, Ohio, USA). The Ad vectors (AdFc $\gamma$ RIIA or AdNull) were administered intratracheally $\left(10^{9}\right.$ plaque-forming units [PFU] in $100 \mu \mathrm{L} 0.9 \% \mathrm{NaCl}$ ). Naive animals were used as controls. Forty-eight hours after administration, the animals were sacrificed (pentobarbital overdose intraperitoneally) and the lungs were removed. Total RNA was extracted (RNA Extraction Kit) and transferred $(10 \mu \mathrm{g} /$ lane $)$ to nylon membranes after electrophoretic separation through a $1 \%$ agarose gel. The membranes were hybridized using a human Fc $\gamma$ RIIA cDNA probe labeled with $\left.{ }^{32} \mathrm{P}\right] \mathrm{dCTP}$ (Random Primer Labeling Kit) for 2 hours using standard methods (25). A ${ }^{32}$ P-labeled human GAPDH probe was used as a positive control (26). To analyze the tissue expression and distribution of FcyRIIA in the lungs of the animals, the lungs of the infected animals were harvested 48 hours after administration of AdFc $\gamma$ RIIA or AdNull, as were those of uninfected animals. The lungs were inflated with $4 \%$ paraformaldehyde, fixed for 24 hours, and then transferred to $70 \%$ ethanol. Immunohistochemical staining for the FcyRII was done on 5-mm sections using the antiFc $\gamma$ RII antibody IV.3 (Medarex Inc.); an IgG2b-matched antibody was used as control.

Clearance of $P$. aeruginosa from the lung. To assess the clearance of $P$. aeruginosa from the lung after Ad-mediated transfer of Fc $\gamma$ RIIA or Fc $\gamma$ RIIIA cDNA, these adenoviral constructs or, as a control, either AdNull or no Ad (naive controls), was administered intratracheally $\left(10^{9}\right.$ PFU in $100 \mu \mathrm{L} 0.9 \% \mathrm{NaCl}$ ) to anesthetized female Sprague-Dawley rats (250-300 g). Forty-eight hours later, the animals were infected intratracheally with $2 \times$ $10^{8}$ CFU of opsonized P. aeruginosa (PAO1 nonmucoid laboratory strain) (29). The opsonized bacteria were prepared as has already been described for the in vitro experiments. The bacteria were grown at $37^{\circ} \mathrm{C}$ in tryptic soy broth to the midlog phase, washed in PBS, and opsonized by incubation for 30 minutes with rabbit antiPAO1 polyclonal antibody (1:200 dilution) at $37^{\circ} \mathrm{C}$. After 20 hours, the animals were sacrificed; the lungs were removed, weighed, homogenized in $0.9 \% \mathrm{NaCl}$; and then the homogenate was incubated on ice for $20 \mathrm{~min}$ utes with $0.5 \%$ Triton X-100 to release intracellular bacteria (30). Bacterial counts were determined by 18 -hour cultures of serial dilutions at $37^{\circ} \mathrm{C}$ on $1.5 \%$ MacConkey agarose plates and were expressed as CFU per gram of lung tissue. The number of bacteria reflects the total number present in the lung at the time of sacrifice.

As another measure of the ability of AdFc $\gamma$ RIIA gene transfer to inhibit the growth of bacteria from the lung, the experiments were performed in mice deficient in the Fc $\gamma$ receptor $\gamma$ subunit (31). These immunocompromised animals do not express Fc $\gamma \mathrm{RI}$ and Fc $\gamma \mathrm{RIII}$ in phagocytic cells, and they lack the capacity to phagocytize antibodycoated particles $(31,32)$. Animals $(6-8$ weeks old) were anesthetized with intramuscular injection of ketamine $(200 \mathrm{mg} / \mathrm{kg}$ ) and xylazine $(10 \mathrm{mg} / \mathrm{kg})$. The Ad vectors (AdFcyRIIA or AdNull) were administered intratracheally $\left(10^{9} \mathrm{PFU}\right.$ in $\left.100 \mu \mathrm{L} 0.9 \% \mathrm{NaCl}\right)$. After 48 hours, animals were infected intranasally with $4 \times 10^{7} \mathrm{CFU}$ of $P$. aeruginosa (PAO1 strain) opsonized with polyclonal rabbit antiPAO1 antibody as already described here. After 20 hours, the animals were sacrificed, the lung was removed, and bacterial counts were determined as already described.

Statistical evaluation. The results are expressed as mean \pm SEM. Statistical comparisons were made using the unpaired 2-tailed Student's $t$ test.

\section{Results}

AdFc 2 RIA expression in A549 cells. Several lines of evidence demonstrated that Ad-mediated FcyRIIA cDNA gene 
transfer results in expression of the FcyRIIA cDNA in the normally nonphagocytic A549 cells. To evaluate the ability of the AdFc $\gamma$ RIIA vector to transfer and express human FcyRIIA in vitro, the A549 cells were infected with AdFc $\gamma$ RIIA and the infected cells were evaluated for Fc $\gamma$ RIIA mRNA transcripts by Northern analysis (Figure 1a). Noninfected cells demonstrated no FcyRIIA mRNA transcripts, whereas AdFc $\gamma$ RIIA-infected cells showed 1.3 $\mathrm{kb}$ Fc $\gamma R$ RIA mRNA transcripts in a dose-dependent manner (Figure 1a). Control GAPDH mRNA transcripts were similar in all samples (Figure 1a). Immunohistochemical assessment using an anti-Fc $\gamma$ RIIA mAb demonstrated positive staining for Fc $\gamma$ RIIA on the surface of A549 cells infected with AdFc $\gamma$ RIIA (Figure 1d). In contrast, no staining was observed in AdFcyRIIA-infected cells incubated with isotype-matched control $\mathrm{mAb}$ (mouse IgG2b; Figure $1 \mathrm{e})$, in AdNull-infected cells assessed with the antiFcyRIIA antibody (Figure 1c), or in noninfected cells incubated with anti-Fc $\gamma$ RIIA antibody (Figure 1b). Quantitative expression of Fc $\gamma$ RIIA on the cell surface was evaluated by flow cytometry (Figure 1f). This analysis demonstrated that $92 \%$ of the cells were positive after AdFc $\gamma$ RIIA infection at an moi of 10. No expression of Fc $\gamma$ RIIA was demonstrated in noninfected or in AdNull-infected A549 cells.

Function of Fc $\gamma R I I A$ after in vitro Ad-mediated Fc $\gamma R I I A$ gene transfer. To demonstrate that in vitro AdFc $\gamma$ RIIAmediated transfer of the Fc $\gamma$ RIIA cDNA conferred to the nonphagocytic A549 lung epithelial cells the functional ability to bind and internalize opsonized particulates, A549 cells were infected with the AdFc $\gamma$ RIIA vector and the cells were evaluated for binding and internalization of IgG-opsonized SRBCs (Figure 2). Neither binding nor phagocytosis of nonopsonized SRBCs was observed in naive cells or cells infected with AdNull, AdFc $\gamma$ RIIA mutant, or AdFc $\gamma$ RIIA (not shown). No binding of opsonized SRBCs was observed by light microscopy in naive or AdNull-infected cells (Figure 2, a and b), whereas markedly increased binding was observed in the cells previously infected with the AdFc $\gamma$ RIIA mutant (as expected, given that mutant mediates binding but not internalization) (Figure 2c) or with AdFc $\gamma$ RIIA (Figure $2 \mathrm{~d}$ ). In contrast, although phagocytosis of opsonized SRBCs was not observed in naive cells or AdNull-infected cells (Figure 2, e and $\mathrm{f}$ ), striking phagocytosis was noted in the AdFc $\gamma$ RIIA-infected cells (Figure $2 \mathrm{~h}$ ) but not in AdFcyRIIA mutant-infected cells (Figure 2g).

${ }^{51} \mathrm{Cr}$-labeled SRBCs were used to quantify binding and phagocytosis after Ad-mediated gene transfer of FcyRIIA (Figure 3). Naive cells or cells infected with AdNull, AdFc $\gamma$ RIIA mutant, or AdFc $\gamma$ RIIA showed minimal to absent binding of nonopsonized SRBCs (Figure 3a). No binding of opsonized SRBCs was observed in the naive and AdNull-infected controls, but binding of opsonized SRBCs was evident in the cells infected with AdFcyRIIA, as well as in cells infected with the AdFcyRIIA mutant as shown in the morphologic studies (Figure 2). This is because the mutant mediates binding but not internalization (Figure 3b: $P<0.0004$ for AdFc $\gamma$ RIIA and AdFc $\gamma$ RIIA mutant compared with naive and AdNull; $P<0.0001$ for AdFc $\gamma$ RIIA mutant with opsonized SRBCs compared with AdFc $\gamma$ RIIA mutant with nonopsonized SRBCs; and $P<0.0001$ for
AdFcyRIIA with opsonized SRBCs compared with AdFc $\gamma$ RIIA with nonopsonized SRBCs). Naive cells or cells infected with AdNull, AdFcyRIIA mutant, or AdFc $\gamma$ RIIA showed minimal phagocytosis of nonopsonized SRBCs (Figure 3c). In marked contrast, the AdFc $\gamma$ RIIA-infected cells showed markedly increased phagocytosis of opsonized SRBCs compared with that of AdFc $\gamma$ RIIA mutant-infected cells, AdNull-infected cells, and naive controls $(P<0.002$, all comparisons; Figure $3 \mathrm{~d})$. The AdFcyRIIA-infected cells also showed markedly increased phagocytosis of opsonized SRBCs compared with all conditions of infection with nonopsonized SRBCs $(P<0.001$, all comparisons; Figure 3, c and d). Small changes were seen with the AdNull vector-infected cells on binding of nonopsonized and opsonized SRBCs, as well as phagocytosis of nonopsonized SRBCs, but these were significantly less than those observed with the AdFcyRIIA-infected cells and might reflect effects of the Ad vector per se on cellular processes.

The uptake of bacteria after AdFc $\gamma$ RIIA transfer was evaluated by incubation of A549 cells with opsonized Pseudomonas. Colony counts from cells infected with AdFc $\gamma$ RIIA were altered 5-fold, compared with uninfected cells; 3.3-fold, compared with AdNull cells; and 3-fold compared with AdFcyRIIA mutant-infected cells (not shown). Similarly, clearance of Pseudomonas was increased to $45 \%$ in HS-24 cells infected with AdFc $\gamma$ RIIA, compared with uninfected cells $(14 \%)$ or cells infected with AdFcyRIIA mutant (17\%; data not shown). Enhanced clearance was also seen in BET-1A cells (a bronchial epithelial cell line) infected with $S$. aureus (46\% compared with controls) after AdFc $\gamma$ RIIA transfer (not shown).

In vivo expression and function of Fc $\gamma$ RIIA in the lung. To demonstrate the ability of AdFcyRIIA to transfer and express human FcyRIIA in the lung in vivo, female Sprague-Dawley rats were infected intratracheally with AdFc $\gamma$ RIIA and, as a control, AdNull, and Northern analysis was used to evaluate Fc $\gamma$ RIIA mRNA transcripts. The lung infected in vivo with AdFc $\gamma$ RIIA expressed the 1.3-kb Fc $\gamma$ RIIA mRNA transcript, whereas noninfected (naive) animals and animals infected with AdNull demonstrated no Fc $\gamma$ RIIA mRNA transcripts (Figure 4). In contrast, control GAPDH mRNA transcripts were similar in all conditions. Immunohistochemical analysis of the expression of FcyRIIA in the lungs of the infected animals demonstrated abundant staining of cells expressing Fc $\gamma$ RIIA in the lung parenchyma of the animals that had received AdFc $\gamma$ RIIA, but not in the AdNull-infected (Figure 5) animals. Sections of naive animals looked similar to those of AdNull-infected animals (data not shown).

Evaluation of the function of the Fc $\gamma$ RIIA expressed in the lung after intratracheal administration of the AdFc $\gamma$ RIIA vector demonstrated that Ad-mediated Fc $\gamma$ RIIA cDNA gene transfer in vivo enhances clearance of opsonized bacteria from the lung of experimental animals over a 20-hour period (Figure 6). In this regard, rats infected with AdFc $\gamma$ RIIA or AdF $\gamma$ RIIIA cleared bacteria from the lung more efficiently than did animals infected with the AdNull control vector or naive animals (Figure 6a; $P<0.02$ AdFc $\gamma$ RIIA and AdFc $\gamma$ RIIIA compared with AdNull and controls). There was no significant difference between the AdNull-infected ani- 
mals compared with the controls $(P>0.1)$, although the number of bacteria in the AdNull-infected animals was slightly decreased compared with the controls. Likewise, clearance of bacteria in the Fc $\gamma$ receptor $\gamma$ subunit-knockout mice was also enhanced in animals infected with AdFc $\gamma$ RIIA compared with animals infected with AdNull (Figure 6b; $P<0.03$ ). All animals sur- vived the challenge with the opsonized bacteria for the period observed.

\section{Discussion}

Expression of Fc $\gamma$ receptors on the surface of phagocytic cells conveys to the cells the ability to recognize, bind, and internalize IgG-opsonized particulate antigens and

\section{Figure 1}

Expression of FcyRIIA by A549 cells after Ad-mediated gene transfer. Cells were infected with AdFcyRIIA and/or AdNull for 48 hours at 1 or 10 moi. Noninfected cells were used as negative controls. (a) Expression of FcyRIIA mRNA assessed by Northern analysis. Hybridized with human Fc $\gamma$ RIIA cDNA probe (top); hybridized with a human GAPDH cDNA probe (bottom). Lane 1: naive control; lane 2: infected with AdFc $\gamma$ RIIA moi 1; lane 3: infected with AdFc $\gamma$ RIIA moi 10. The sizes of transcripts are indicated. (b-e) Expression of FcyRIIA protein on the cell surface measured by immunohistochemistry. The cells were stained with anti-Fc $\gamma$ RIIA $\mathrm{mAb}$, followed by alkaline-phosphatase-conjugated goat-anti mouse IgG and alkaline-phosphatase substrate and counterstained with hematoxylin. (b) Naive cells. (c) AdNull-infected cells (moi 10). (d) AdFcyRllA-infected cells (moi 10). (e) AdFcyRlIA-infected cells (moi 10) incubated with isotypematched control antibody. All panels are original magnification $\times 400$. (f) Expression of FcyRIIA protein on the cell surface assessed by immunostaining and flow cytometry. Cells were incubated with anti-FcyRIIA mAb, followed with FITC-conjugated goat anti-mouse $F(a b) 2 \lg G$ and assessed by flow cytometry in comparison to isotype-matched controls. Shown is analysis of naive controls, AdNull-infected cells (moi 10), and AdFcyRIIA-infected cells (moi 10). The horizontal line indicates the region considered positive. a
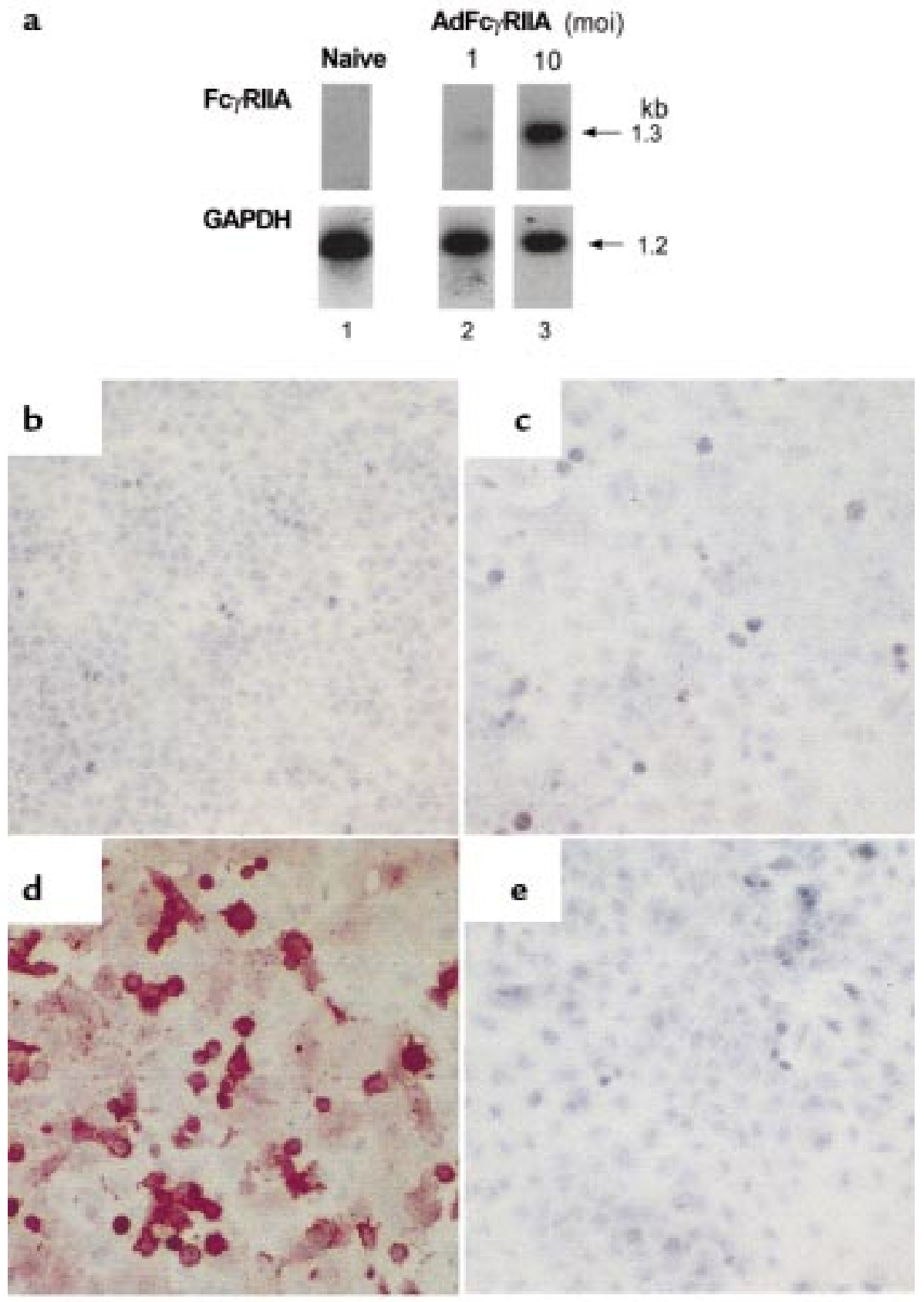

f

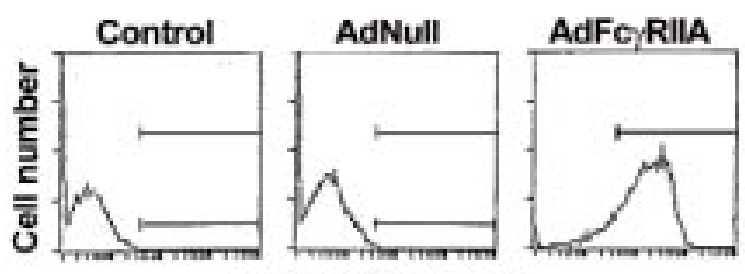

Relative light units 
Figure 2

AdFcyRIIA induced binding and phagocytosis of opsonized SRBCs in vitro. A549 cells grown on coverslip dishes were infected with AdFcyRIIA, AdFc $\gamma R$ RIIA mutant, and AdNull at 10 moi. After 48 hours, the cells were incubated with IgG-coated SRBCs for 60 minutes. To evaluate binding, cells were washed, fixed, and stained by Giemsa stain. To evaluate phagocytosis, cells were washed, SRBCs bound to the cell surface were lysed, and the A549 cells were fixed and stained by Giemsa stain or eosin as indicated. (a) Binding of opsonized SRBCs by naive cells. (b) Binding of opsonized SRBCs by AdNull-infected cells. (c) Binding of opsonized SRBCs by AdFcyRIIA mutant-infected cells. (d) Binding of opsonized SRBCs by AdFcyRIIA-infected cells. (e) Phagocytosis of opsonized SRBCs by naive noninfected cells. (f) Phagocytosis of opsonized SRBCs by AdNull-infected cells. (g) Phagocytosis of opsonized SRBCs by AdFcyRIIA mutant-infected cells. (h) Phagocytosis of opsonized SRBCs by AdFcyRIIA-infected cells. Large panels are original magnification $\times 400$ (Giemsa stain). Shown in the insets are light microscopy of original magnification $\times 1,000$ for $\mathbf{a}-\mathbf{d}$ (Giemsa stain) and fluorescent microscopy of original magnification $\times 1,000$ (eosin) for $\mathbf{e}-\mathbf{h}$.

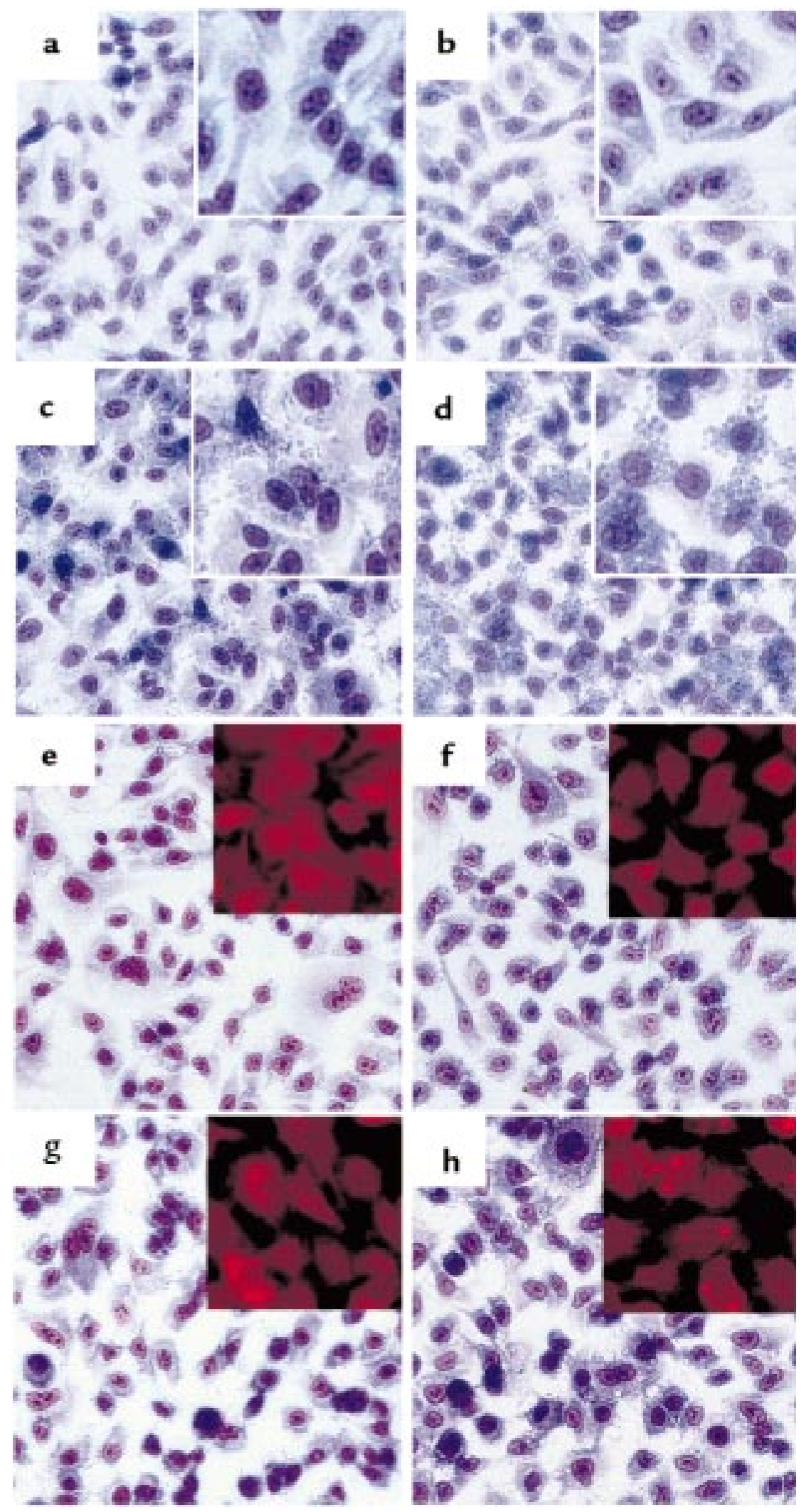


immune complexes (7-13). The present study demonstrates the ability of Ad-mediated Fc $\gamma$ receptor cDNA gene transfer to genetically modify normally nonphagocytic lung epithelial cells to functional phagocytic cells capable of enhancing host defense against a bacterial challenge. In this context, in vitro infection of a lung epithelial cell line with the AdFcyRIIA gene transfer vector resulted in expression of Fc $\gamma$ RIIA mRNA and expression of functional Fc $\gamma$ RIIA protein on the cell surface, enabling normally nonphagocytic cells to bind and internalize IgG-opsonized SRBCs. Importantly, in vivo intratracheal administration of the AdFc $\gamma$ RIIA gene transfer vector or the AdFc $\gamma$ RIIIA/Fc $\gamma$ RIIA chimeric gene transfer vector resulted in expression of the Fc $\gamma$ receptor cDNA in the lung of experimental animals and enhanced clearance of opsonized $P$. aeruginosa from the lungs after intratracheal challenge.

Fcyreceptors. The Fc domain of antibodies binds to specialized cell-surface Fc receptors (FcR) (7-13). These Fc receptors are defined by their specificity for immunoglobulin isotypes. Fc $\gamma$ receptors (IgG-specific Fc receptors) are membrane glycoproteins with extracellular domains related to a C2-set of immunoglobulin related domains, a single membrane-spanning domain, and an intracytoplasmic domain of variable length (33). Three subclasses of Fc $\gamma$ receptors have been identified: Fc $\gamma$ RI (CD 64), Fc $\gamma$ RII (CD 32), and Fc $\gamma$ RIII (CD16) (7-13). Fc $\gamma$ RIIA is the only allotype of Fc $\gamma$ receptors that efficiently recognizes IgG2 (7-13), an IgG isoform that plays an important role in the defense against infection with bacteria such as Streptococcus pneumoniae, Haemophilus influenzae, Neisseria meningitidis, and P. aeruginosa (34-36), and that can directly mediate a phagocytic signal in the absence of an accessory chain or in the absence of other Fc $\gamma$ receptors $(19,37)$. Fc $\gamma$ RIIA exists in 2 allelic forms that differ in amino acid at position 131 (arginine R131/histidine $\mathrm{H} 131$ ) in the second immunoglobulin-like domain $(38,39)$. This genetic polymorphism is common, with $25 \%$ of Caucasians being homozygous for R131/R131 (39). Interestingly, polymorphisms at this site influence the binding of IgG2 to FcyRIIA, with individuals homozygous for R131/R131 unable to bind IgG2-opsonized bacteria efficiently. Consistent with this in vitro observation, these individuals have a higher incidence of infections with encapsulated bacteria and have an increased mortality when infected with encapsulated bacteria $(35,36)$.

Transfer and expression of Fc $\gamma R$ RIA to nonphagocytic cells. a

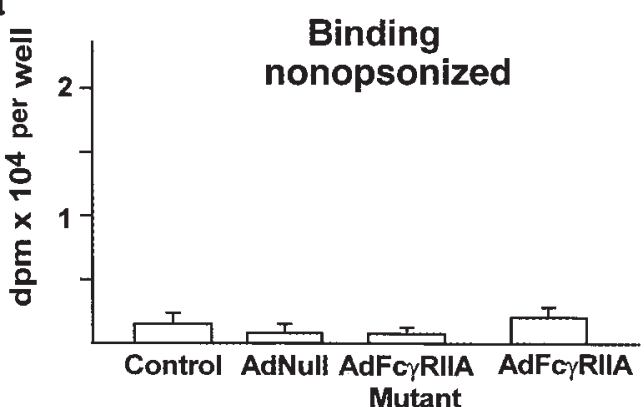

C

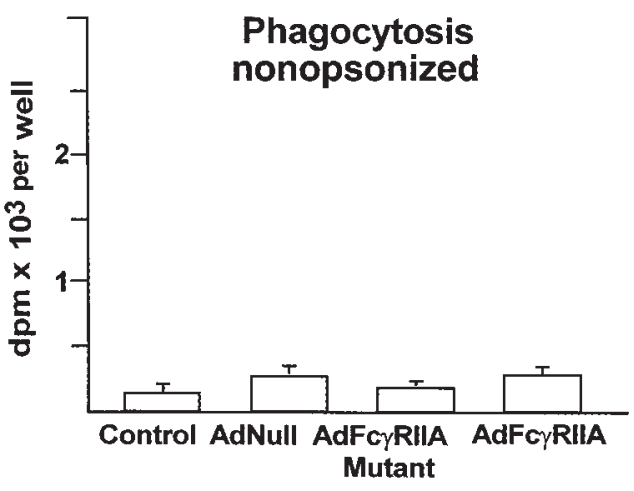

b

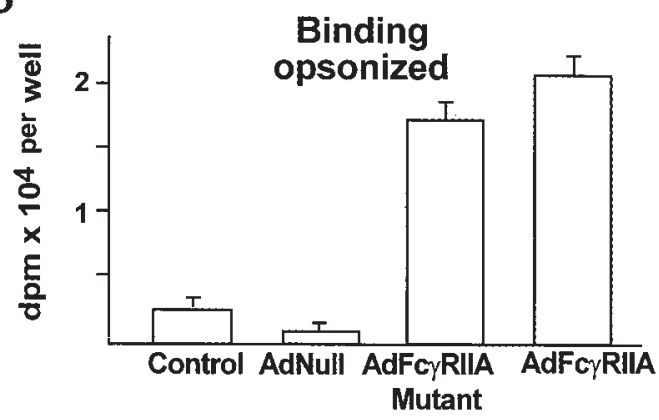

d

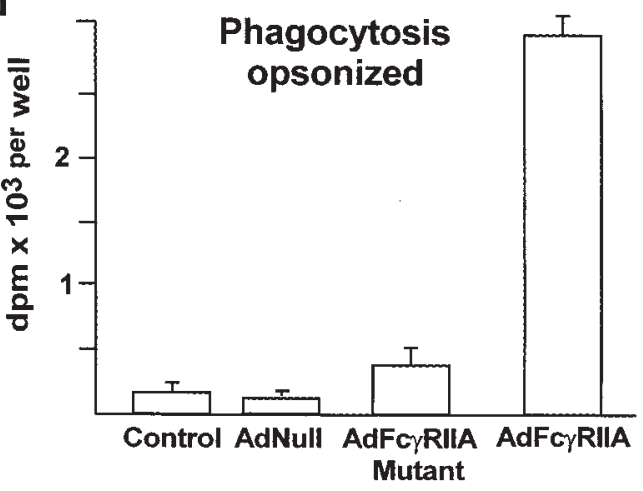

Figure 3

Quantitative assessment of binding and phagocytosis of SRBCs by A549 cells after Ad-mediated FcyRIIA cDNA gene transfer. A549 cells were infect-

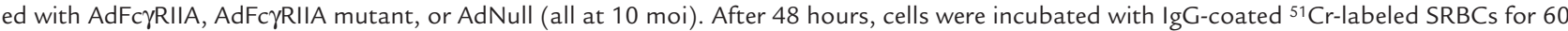
minutes, or as a control, with nonopsonized ${ }^{51} \mathrm{Cr}$-labeled SRBCs for 60 minutes. To evaluate binding of IgG-coated SRBCs, the cells were washed and radioactivity of the lysate was quantified. To evaluate phagocytosis, the cells were washed and the SRBCs bound to the cell surface were removed by lysis. The A549 cells were then lysed, and radioactivity of the lysate was quantified. (a) Binding of nonopsonized SRBCs. (b) Binding of opsonized SRBCs. (c) Phagocytosis of nonopsonized SRBCs. (d) Phagocytosis of opsonized SRBCs. Shown are means \pm SEM of activity (disintegrations per minute) per well of triplicate assessments. 


\section{Figure 4}

Ad-mediated in vivo expression of the FcyRIIA cDNA in the lung. SpragueDawley rats were infected intratracheally with AdFcyRIIA and AdNull $\left(10^{9}\right.$ PFU). After 48 hours, total RNA isolated from the lung was evaluated using Northern analysis. Human FcyRIIA probe (top); human GAPDH probe (bottom). Lane 1: naive controls; lane 2: AdNull; lane 3: AdFcyRIIA vector. The sizes of transcripts are indicated.
Naive AdNull AdFo,RIIA

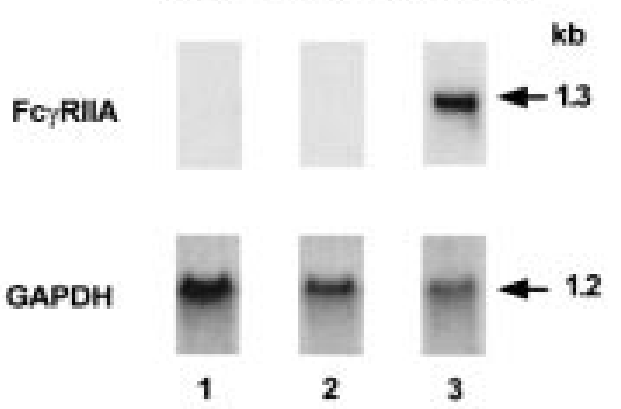

contrast, infection with AdFc $\gamma$ RIIA mutant (lacking a functional intracytoplasmic domain) induced only binding, but not phagocytosis, of IgG-opsonized SRBCs. Binding and phagocytosis were not observed by naive cells and cells infected with AdNull, although there were some minor changes within AdNull-infected cells, compared with controls, on binding of nonopsonized and opsonized red cells. These changes were significantly less than those observed with AdFcyRIIA and probably are due to effects of the Ad vector per se on cellular processes as has been observed in other systems (41). Furthermore, in vitro infection of lung epithelial cells with AdFcyRIIA led to increased uptake of Pseudomonas or $S$. aureus. In vivo administration to the respiratory epithelial surface of the AdFc $\gamma$ RIIA vector, but not the control
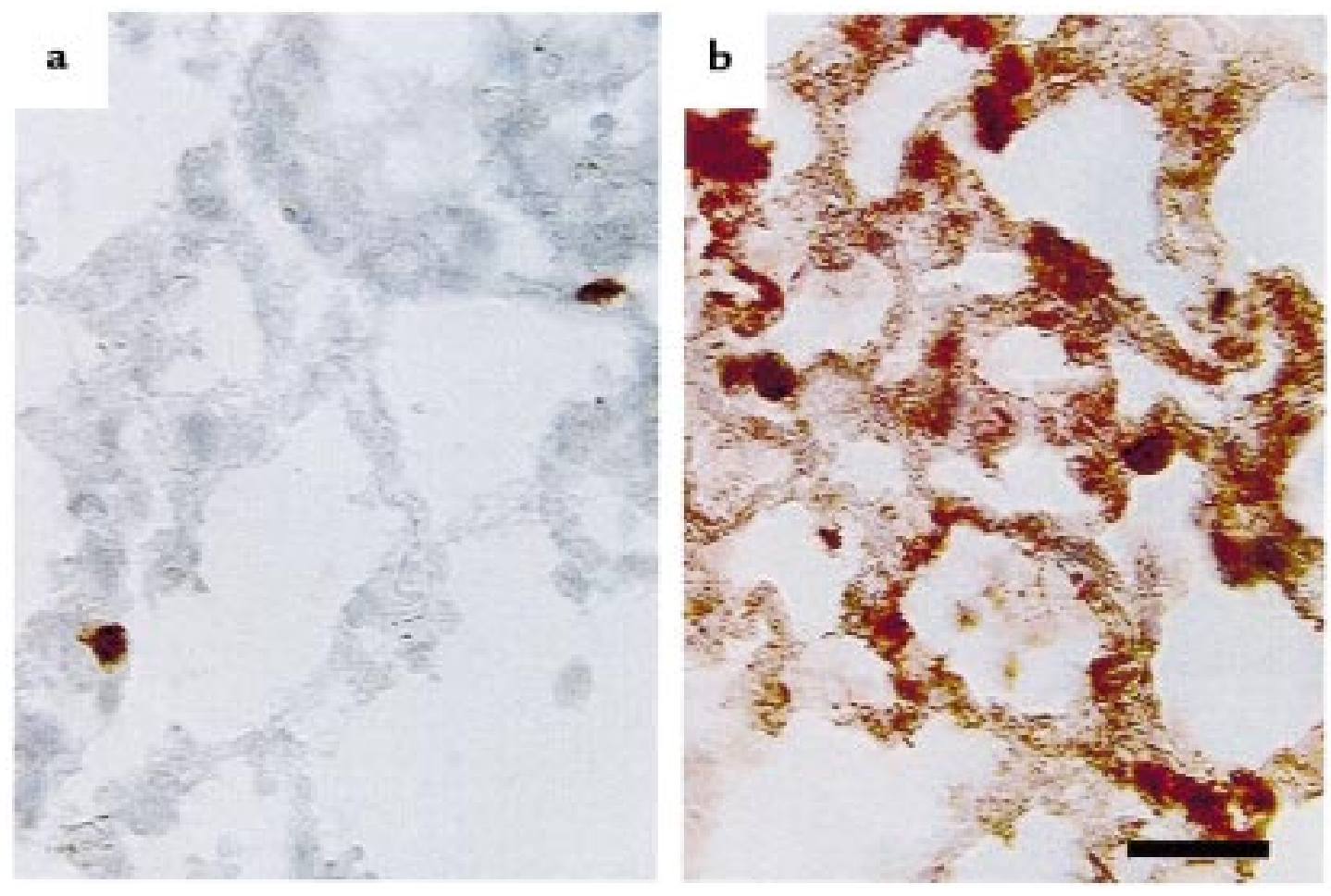

\section{Figure 5}

Ad-mediated in vivo expression of FcyRIIA in the lung. Sprague-Dawley rats were infected intratracheally with AdFcyRIIA and AdNull (109 PFU). After 48 hours, the lungs were harvested and fixed and expression of FcyRII was evaluated by immunohistochemistry using the anti-FcyRIIA antibody IV.3. (a) AdNull. (b) AdFcyRIIA. The positive staining on alveolar macrophages in a is due to endogenous peroxidase activity in these cells. Scale bar $=50 \mu \mathrm{M}$. 
a

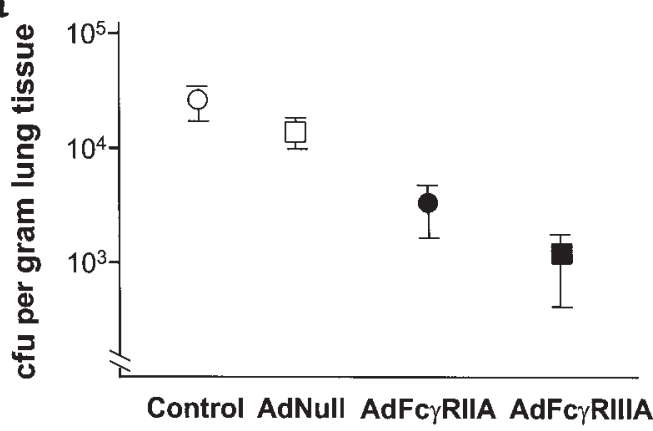

b

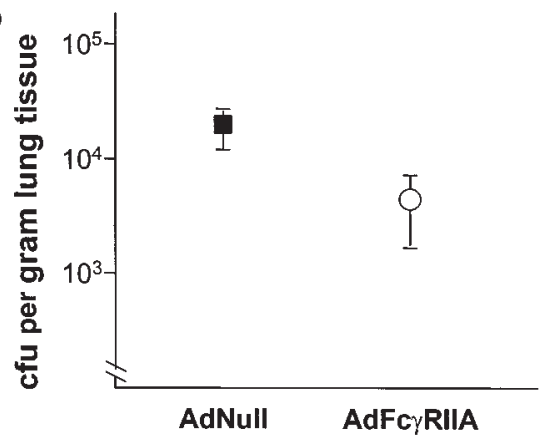

\section{Figure 6}

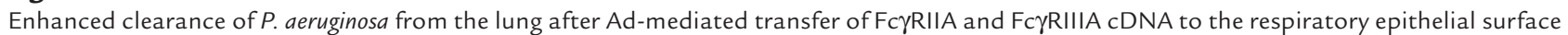
of experimental animals. (a) Enhanced clearance in normal rats. Sprague-Dawley rats were infected intratracheally with AdFc $\gamma R \mathrm{Il} A$, AdFcyRIIIA, or AdNull ( $\left.10^{9} \mathrm{PFU}\right)$. After 48 hours, the animals were challenged via the intratracheal route with $10^{8} \mathrm{CFU}$ of the PAO1 strain of P. aeruginosa opsonized with rabbit anti-PAO1 polyclonal antibody. After 20 hours, animals were sacrificed, the lungs were removed, and bacterial counts of the lysates were determined. Data are expressed as CFU of PAO1 per gram of lung tissue. Shown are means of CFU per gram

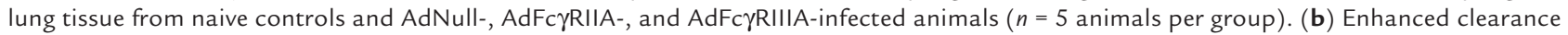
in Fc $\gamma$ receptor-knockout mice. Fc $\gamma$ receptor-knockout mice were infected intratracheally with AdFc $\gamma$ RIIA or AdNull (10 $\mathrm{PFU})$. After 48 hours, the mice were infected intranasally with $4 \times 10^{7} \mathrm{CFU}$ of the PAO1 strain of $P$. aeruginosa opsonized with rabbit anti-PAO1 polyclonal antibody. After 20 hours, animals were sacrificed, the lungs were removed, and bacterial counts of the lysates were determined. Data are expressed as CFU of PAO1 per gram of lung tissue. Shown are means of CFU per gram of lung tissue from AdNull-infected animals $(n=7)$ and AdFcyRIIAinfected animals $(n=10)$. The data in $\mathbf{a}$ and $\mathbf{b}$ represent mean \pm SEM.

AdNull vector, was associated with expression of FcyRIIA mRNA transcripts in the lung. There is overwhelming evidence that in vivo administration of Ad vectors to the respiratory epithelium is associated with expression of the transgene carried by the vector exclusively in the respiratory epithelium $(15,16,42)$. Consistent with these reports, the present study demonstrates expression of Fc $\gamma$ RIIA in the lung parenchymal cells after intratracheal administration of AdFc $\gamma$ RIIA.

$P$. aeruginosa and airway inflammation. $P$. aeruginosa is a ubiquitous, Gram-negative aerobic rod with polar, monotrichous flagella and protein structures on the surface (pili) that are responsible for adherence to respiratory epithelium (43). Pseudomonas rarely causes infection in the normal host, but as an efficient opportunistic pathogen, it is commonly isolated during nosocomial infections in immunocompromised individuals (44) and is a major pathogen in individuals with cystic fibrosis (45).

In the present study, enhanced clearance of opsonized $P$. aeruginosa from the lungs of experimental animals was observed after intratracheal administration of AdFc $\gamma$ RIIA or an AdFc $\gamma$ RIIIA/Fc $\gamma$ RIIA chimeric receptor in comparison with naive controls or AdNull-infected (no transgene) animals. The small decrease in the number of bacteria present in the animals infected with AdNull compared with naive controls was not significant and is potentially a reflection of inflammation induced by the Ad vector per se. Similarly, Ad-mediated transfer of Fc $\gamma$ RIIA cDNA to the lungs of Fc $\gamma$ receptor $\gamma$ chain-knockout mice $(31,32)$ led to increased clearance of Pseudomonas. Based on the in vitro observations in the lung epithelial cell line, the mechanism by which the AdFc $\gamma$ RIIA vector conveys enhanced clearance of opsonized Pseudomonas to the lung in normal rats and in the Fc $\gamma$ receptor $\gamma$ chain-knockout mice is likely due to the internalization and inhibition of bacterial growth caused by the enhanced expression of Fc $\gamma$ RIIA on the surface of epithelial cells. It is very unlikely that increased clearance of bacteria is due to efficient gene transfer to professional phagocytic cells, as they are poor targets for Ad-mediated gene transfer and were not different in the Fc $\gamma$ RIIA-positive histochemical sections compared with AdNull or uninfected controls $(46,47)$.

Possible clinical significance. One possible clinical application of this approach may be in the enhancement of bacterial clearance from the airways in individuals with cystic fibrosis. Another application might be in in vivo enhancement of the impaired phagocytosis in diseases such as systemic lupus erythematosus and chronic liver and kidney disease, in which phagocytosis of IgGopsonized bacteria is impaired because of the downregulation of the Fc $\gamma$ receptors (48-50). There are reports of using Ad-mediated gene transfer of either IL-12 and IFN- $\gamma$ to enhance the clearance of bacteria (51-53), and thus, it might be possible to use the combination of more than one gene transfer approach to enhance further the antibacterial defense of the lung and other organs.

\section{Acknowledgments}

We thank P. Leopold and B. Ferris for assistance with the imaging studies, and N. Mohamed for helping to prepare this manuscript. These studies were supported, in part, by the National Institutes of Health (P01 HL-51746, P01 HL-59312, HL-27068, HL-77168, and AI-22193); Will Rogers Memorial Fund; Cystic Fibrosis Foundation; GenVec Inc.; and InKine Pharmaceutical Co. Inc. 
1. Reynolds, H.Y. 1997. Integrated host defense against infections. In The lung: scientific foundations. R.G. Crystal, J.B. West, E.R. Weibel, and P.J. Barnes, editors. Lippincott-Raven Publishers. Philadelphia, PA. 2353-2365.

2. Martin, E., Ganz, T., and Lehrer, R.I. 1995. Defensins and other endogenous peptide antibiotics of vertebrates. J. Lenkoc. Biol. 58:128-136.

3. Ganz, T., and Weiss, J. 1997. Antimicrobial peptides of phagocytes and epithelia. Semin. Hematol. 34:343-354.

4. Bezdicek, P., and Crystal, R.G. 1997. Pulmonary macrophages. In The lung: scientific foundations. R.G. Crystal, J.B. West, E.R. Weibel, and P.J. Barnes, editors. Lippincott-Raven Publishers. Philadelphia, PA. 859-875.

5. Holland, S.M., and Gallin, J.I. 1997. Neutrophils. In The lung: scientific foundations. R.G. Crystal, J.B. West, E.R. Weibel, and P.J. Barnes, editors. Lippincott-Raven Publishers. Philadelphia, PA. 877-904.

6. Greenberg, S., and Silverstein, S.C. 1993. Phagocytosis. In Fundamental immunology. W.E. Paul, editor. Raven Press. New York, NY. 941-964.

7. Ravetch, J.V., et al. 1986. Structural heterogeneity and functional domains of murine immunoglobulin G Fc receptors. Science. 234:718-725.

8. Ravetch, J.V., and Kinet, J.P. 1991. Fc receptors. Annu. Rev. Immunol. 9:457-492.

9. Sandor, M., and Lynch, R.G. 1993. The biology and pathology of FC receptors. J. Clin. Immunol. 13:237-246.

10. De Haas, M., Vossebeld, P.J., von dem Borne, A.E., and Roos, D. 1995. Fc $\gamma$ receptors of phagocytes. J. Lab. Clin. Med. 126:330-341.

11. Ravetch, J.V. 1997. Fc receptors. Curr. Opin. Immunol. 9:121-125.

12. Ravetch, J.V. 1994. Fc receptors: rubor redux. Cell. 78:553-560.

13. McKenzie, S.E., and Schreiber, A.D. 1998. Fc $\gamma$ receptors in phagocytes. Curr. Opin. Hematol. 5:16-21.

14. Rosenfeld, M.A., et al. 1991. Adenovirus-mediated transfer of a recombinant alpha 1-antitrypsin gene to the lung epithelium in vivo. Science. 252:431-434

15. Rosenfeld, M.A., et al. 1992. In vivo transfer of the human cystic fibrosis transmembrane conductance regulator gene to the airway epithelium. Cell. 68:143-155.

16. Mastrangeli, A., et al. 1993. Diversity of airway epithelial cell targets for in vivo recombinant adenovirus-mediated gene transfer. $J$. Clin. Invest. 91:225-234.

17. Crystal, R.G., et al. 1994. Administration of an adenovirus containing the human CFTR cDNA to the respiratory tract of individuals with cystic fibrosis. Nat. Genet. 8:42-51.

18. Brooks, D.G., Qiu, W.Q., Luster, A.D., and Ravetch, J.V. 1989. Structure and expression of human IgG FcRII(CD32). Functional heterogeneity is encoded by the alternatively spliced products of multiple genes. J. Exp. Med. 170:1369-1385.

19. Indik, Z., Kelly, C., Chien, P., Levinson, A.I., and Schreiber, A.D. 1991. Human Fc $\gamma$ RII, in the absence of other Fc $\gamma$ receptors, mediates a phagocytic signal. J. Clin. Invest. 88:1766-1771.

20. Hersh, J., Crystal, R.G., and Bewig, B. 1995. Modulation of gene expression after replication-deficient, recombinant adenovirus-mediated gene transfer by the product of a second adenovirus vector. Gene Ther 2:124-131.

21. Mitchell, M.A., et al. 1994. Substitutions and deletions in the cytoplasmic domain of the phagocytic receptor Fc $\gamma$ RIIa: effect on receptor tyrosine phosphorylation and phagocytosis. Blood. 84:1753-1759.

22. Hunter, S., et al. 1998. Inhibition of Fc $\gamma$ receptor-mediated phagocytosis by a nonphagocytic Fc $\gamma$ receptor. Blood. 91:1762-1768.

23. Indik, Z.K., Park, J.G., Hunter, S., and Schreiber, A.D. 1995. The molecular dissection of $\mathrm{Fc} \gamma$ receptor mediated phagocytosis. Blood. 86:4389-4399.

24. Graham, F.L., and Prevec, L. 1991. Manipulation of adenovirus vectors. In Methods in molecular biology. E.J. Murray, editor. Humana Press. Clifton, NJ. 109-128.

25. Sambrook, J., Fritsch, E.F., and Maniatis, T. 1989. Molecular cloning. Cold Spring Harbor Laboratory Press. Plainview, NY

26. Tso, J.Y., Sun, X.H., Kao, T.H., Reece, K.S., and Wu, R. 1985. Isolation and characterization of rat and human glyceraldehyde-3-phosphate dehydrogenase cDNAs: genomic complexity and molecular evolution of the gene. Nucleic Acids Res. 13:2485-2502.

27. Leopold, P.L., et al. 1998. Fluorescent virions: dynamic tracking of the pathway of adenoviral gene transfer vectors in living cells. Hum. Gene Ther. 9:367-378.

28. Falk, L.A. 1995. Measurement of Fc $\gamma$ receptor-mediated binding and phagocytosis. In Current protocols in immunology. J.E. Coligan, A.M. Kruisbeek, E.M. Shevach, and W. Strober, editors. John Wiley \& Sons. New
York, NY. 14.8.1-14.9.5.

29. Holloway, B.W., Krishnapillai, V., and Morgan, A.F. 1979. Chromosomal genetics of Pseudomonas. Microbiol. Rev. 43:73-102.

30. Pier, G.B., et al. 1996. Role of mutant CFTR in hypersusceptibility of cystic fibrosis patients to lung infections. Science. 271:64-67.

31. Takai, T., Li, M., Sylvestre, D., Clynes, R., and Ravetch, J.V. 1994. FcR $\gamma$ chain deletion results in pleiotrophic effector cell defects. Cell. 76:519-529.

32. Vora, K.A., Ravetch, J.V., and Manser, T. 1997. Amplified follicular immune complex deposition in mice lacking the Fc receptor $\gamma$-chain does not alter maturation of the B cell response. J. Immunol. 159:2116-2124.

33. Williams, A.F., and Barclay, A.N. 1988. The immunoglobulin superfamily: domains for cell surface recognition. Annu. Rev. Immunol. 6:381-405.

34. Pressler, T, et al. 1988. Increased IgG2 and IgG3 concentration is associated with advanced Pseudomonas aeruginosa infection and poor pulmonary function in cystic fibrosis. Acta Paediatr. Scand. 77:576-582.

35. Bredius, R.G., et al. 1994. Fc $\gamma$ receptor IIa (CD32) polymorphism in fulminant meningococcal septic shock in children. J. Infect. Dis. 170:848-853

36. Sanders, L.A., et al. 1994. Fc $\gamma$ receptor IIa (CD32) heterogeneity in patients with recurrent bacterial respiratory tract infections. J. Infect. Dis. 170:854-861

37. Hunter, S., Kamoun, M., and Schreiber, A.D. 1994. Transfection of an Fc $\gamma$ receptor cDNA induces T cells to become phagocytic. Proc. Natl. Acad. Sci. USA. 91:10232-10236.

38. Warmerdam, P.A., van de Winkel, J.G., Gosselin, E.J., and Capel, P.J. 1990. Molecular basis for a polymorphism of human Fc $\gamma$ receptor II (CD32). J. Exp. Med. 172:19-25.

39. Rascu, A., Repp, R., Westerdaal, N.A., Kalden, J.R., and van de Winkel, J.G. 1997. Clinical relevance of Fc $\gamma$ receptor polymorphisms. Ann. NY Acad. Sci. 815:282-295

40. Tuijnman, W.B., Capel, P.J., and van de Winkel, J.G. 1992. Human lowaffinity IgG receptor Fc $\gamma$ RIIa (CD32) introduced into mouse fibroblasts mediates phagocytosis of sensitized erythrocytes. Blood. 79:1651-1656.

41. Hidaka, C., et al. 1999. CAR-dependent and CAR-independent pathways of adenovirus vector-mediated gene transfer and expression in human fibroblasts. J. Clin. Invest. 103:579-587.

42. Zabner, J., et al. 1994. Safety and efficacy of repetitive adenovirus-mediated transfer of CFTR cDNA to airway epithelia of primates and cotton rats. Nat. Genet. 6:75-83.

43. Pollack, M. 1995. Psendomonas aeruginosa. In Principles and practices of infectious diseases. G.L. Mandell, J.E. Bennett, and R. Dolin, editors. Churchill Livingstone. New York, NY. 1673-1691.

44. Trilla, A. 1994. Epidemiology of nosocomial infections in adult intensive care units. Intensive Care Med. 20(Suppl. 3):S1-S4.

45. Welsh, M.J., Tsui, L.-C., Boat, T.F., and Beaudet, A.L. 1995. Cystic fibrosis. In The metabolic and molecular bases of inherited disease. C.R. Scriver, A.L. Baudet, W.S. Sly, and D. Valle, editors. McGraw-Hill. New York, NY. 3799-3878

46. Noah, T.L., Wortman, I.A., Hu, P.C., Leigh, M.W., and Boucher, R.C. 1996. Cytokine production by cultured human bronchial epithelial cells infected with a replication-deficient adenoviral gene transfer vector or wild-type adenovirus type 5. Am. J. Respir. Cell Mol. Biol. 14:417-424.

47. Worgall, S., et al. 1997. Role of alveolar macrophages in rapid elimination of adenovirus vectors administered to the epithelial surface of the respiratory tract. Hum. Gene Ther. 8:1675-1684.

48. Frank, M.M., Hamburger, M.I., Lawley, T.J., Kimberly, R.P., and Plotz, P.H. 1979. Defective reticuloendothelial system Fc-receptor function in systemic lupus erythematosus. N. Engl. J. Med. 300:518-523.

49. Ruiz, P., Gomez, F., and Schreiber, A.D. 1990. Impaired function of macrophage $\mathrm{Fc} \gamma$ receptors in end-stage renal disease. N. Engl. J. Med. 322:717-722.

50. Gomez, F., Ruiz, P., and Schreiber, A.D. 1994. Impaired function of macrophage Fc $\gamma$ receptors and bacterial infection in alcoholic cirrhosis. N. Engl. J. Med. 331:1122-1128.

51. Greenberger, M.J., et al. 1996. IL-12 gene therapy protects mice in lethal Klebsiella pneumonia. J. Immunol. 157:3006-3012.

52. Stoeckle, M.Y., Falck-Pederson, E., Rubin, B.Y., Anderson, S.L., and Murray, H.W. 1996. Delivery of human interferon- $\gamma$ via gene transfer in vitro: prolonged expression and induction of macrophage antimicrobial activity. J. Interferon Cytokine Res. 16:1015-1019.

53. Lei, D., et al. 1997. Activation of alveolar macrophages and lung host defenses using transfer of the interferon- $\gamma$ gene. Am. J. Physiol. 272:L852-L859. 